\title{
The Linguistic Choices in Reproducing Ideology of a Local Folktale
}

\author{
Simon Arsa Manggala \\ English Letters Department \\ Sanata Dharma University \\ Yogyakarta, Indonesia \\ simonarsa@usd.ac.id
}

\begin{abstract}
The purpose of this paper is to identify and describe the linguistic selection in reproducing the ideology in a folktale. Folktales as literatures for children carry didactic ideologies [1] However, the ideologies tend to be transparent by selectively employing linguistic items. Folktales also consequently possess the tendency to be reproduced. To reveal the transparent ideologies is one of the aims of Critical Discourse Analysis (CDA), particularly in revealing the reasons triggering particular conducts [2]. The object of the study is a folktale from South Kalimantan, Indonesia entitled Ampak dan Musang yang Cerdik [3]. The language in the folktale is observed by linguistic toolkits namely the language of evaluation [4] and transitivity analysis from Systemic Functional Grammar [5]. The participants of the study are the students taking Composition II class in English Letters Department, Sanata Dharma University. The students are expected to be able to retell the folktales by their own styles since they learn various styles in composing English texts. Operationally, in this study the participants have to retell the folktale. Later on, the language of the reproduction is observed and compared to the language of the source text. The expected result is that the linguistic selections in the reproduction tend likely to be similar to the linguistic selections in the source text. However, there might be some differences due to the linguistic repertoire of the participants. Hopefully, this paper might be convenient serving as a case of CDA.
\end{abstract}

Keywords-Critical Discourse Analysis, Folktales, Language of Evaluation, Transitivity

\section{INTRODUCTION}

This paper is developed from the perspective that literary reading is open to the readers' viewpoints. This paper observes the way readers perceived particular reading rather than they way the author conceives his/her message. This paper might be also a response to the opposing view that literary reading should only regard the authors' intention and meaning. The author-centered reading might possess a difficulty that for some works there is no access to the authors anymore. Thus, readers' interpretation is plausible. Barthes as mentioned by Bradford mentions that it is free for the readers to interpret a work once the work is published [6]. However, the interpretation should be able to be traced back to the work. In other words, the interpretation should be relatable to the words of the authors. This paper does not intend to neglect the roles of the authors, but this paper provides the evidences from linguistic point of view that readers might draw their own way in reading a work reflected in their reproduction. In sum, this paper regards authors and the readers as the contexts of a work.

This paper employs linguistic analysis since linguistic evidences could provide accommodation to the analysis of the authors' work and to the reproduction of the work. By employing linguistic tools, the language in the works might predict the authors' intention and the readers' interpretation. This paper is close to stylistic analysis since this paper observes the patterns and the effects. Verdonk mentions that style is selected [7]. In a literary work the style in using language is utilized to achieve particular purposes. Having that notion, therefore, authors are assumable to choose particular linguistic tools to achieve particular messages. Inline with that notion, the language in literary works is well selected and undergone long processes of revisions [8]. This paper observes the language in a literary work to underline the didactic purpose of the work. In other words, this paper highlights the use of language in order to teach the target readers and the use of language (by the readers) to perceive the teaching.

Consequently, this paper assumes that both the language uses in the source text by the authors and in the reproduced text are influenced by the contexts of the texts. Relevant context that influences language use in the source text is the purpose. A purpose of children's literature is didactic purpose. Nodelman mentions that children's literature is a didactic literature in nature [1]. This notion brings a consequence that the target readers are expected to learn something while/after they read a particular work. In other words, the target readers need to find the moral values or teachings in the works. To achieve the purpose that the readers learn something, the authors employ particular strategy in using the language. For this paper, the target readers are expected to retell the work. Thus, in the reproduced texts, the purpose is to retell also the moral values or teachings of the source text. The other contexts are possibly the prior knowledge and language competence of the readers.

This paper wants to observe not only the reproduction of the language but also the ideology that it carries. Ideology is defined as a story about the ideal behaviors or conducts of human being [9]. The ideology sets how human beings as members of society should conform their conducts to it. The ideology is set by the society to control the 
members. Simpson defines ideology as the shared assumptions and beliefs by the society [10]. So, an ideology is set by society to control the society itself [11]. In literary works, the ideology is similar to the concept of moral message. A particular story is told to deliver particular moral messages. The moral messages are utilized to shape the target readers.

Reproduction of a work becomes plausible because of the linguistic competence of the reproducers. The language competence of the reproducers influences the language use in any terms. The language use might range from the choice of words, the syntactic structures of the clauses and sentences, to the organization of the texts. In addition, the reproducers might include also their personal backgrounds, understandings, or even beliefs in their reproduction. Verdonk argues that shared beliefs influence literary readers' response [7]. Simpson responds to Saphir-Whorf hypothesis by mentioning the beliefs built by personal backgrounds, knowledge, and understandings "become lexicalized" in the language [10]. This highlights the roles of language analysis in the analysis of the source text and the reproduced one.

Besides the language competence, analysis of literary
work beproduction blausible since reproduction/reinvention of particular texts is common. Some popular works have been reproduced/reinvented. For example, the famous Cinderella story has been reproduced/reinvented by many cultures in many languages [12], [13], [14], [15], [16]. In Indonesia, one of many possible reproductions is the one by Mason entitled A Tale of Two Sister [17]. The story is adjusted to Indonesian contexts, particularly Balinesse contexts. In Vietnam, Cinderella story is reproduced into The Story of Tam and Cam [18] by some adjustments related to Vietnamese cultures. However, this paper does not intend to peruse the different styles as a result of different cultures. This paper wants to provide evidences that literary works are possible to be reinvented by various styles by any readers.

Regarding the readers' viewpoints, the language competence, the possibilities to reproduce literary works, this paper utilizes two linguistic toolkits. The first toolkit is transitivity analysis proposed by Matthiessen and Halliday [5]. Transitivity analysis has been utilized to analyze literary texts [19], [20]. The transitivity analysis focuses on the ideational meanings of language. The ideas and meanings of the language users are represented in the processes in clauses. The analysis observes also the configuration of the processes and the participants. The second toolkit is the Appraisal Analysis by [4]. This analysis focuses on the choice of words in the texts. The choice of words might reveal the evaluation of the participants towards the world.

\section{REVIEW OF PREVIOUS STUDIES}

Previously, the present researcher had presented a similar topic in $11^{\text {th }}$ Conference of English Studies [21]. The paper observed the linguistic choices by students from various levels in an English for international communication course. The underlying background was similar to the present paper that folktales are meant to teach the target readers and possible to be reproduced/reinvented by the readers. The participants of the paper were the representative of four levels in the course. They were selected based on the midterm test result and the personal evaluation of the class instructors. There were only students from mid-beginner, upper-beginner, pre-intermediate, and intermediate levels who returned the forms. The paper intended to check whether the language employed in reproducing the particular folktale was congruent with levels in the course and to observe how the reproduction deliver the ideology of the source text. The source text was a folktale from Javanese culture entitled The Golden Snail. In the discussion, the researcher presented the ideology of the folktale that supernatural beings are prominent in the society. The result showed that the reproduction text tended to maintain the ideology. The most significant number of process was material process. The ratio of the total number of clauses and those containing material process was also increased. In the source text, the material process appeared in $30 \%$ of all the clauses while in the reproduction texts it was near to $50 \%$.

Though the article by Manggala [21] worked on the same topic and methodology, this paper is different from that paper in terms of the participants and the source text as the object. The participants of the present paper are university students majoring English Literatures. Thus, they might have different English language production. In addition, the participants in this present paper take a subject about how to read and to compose various genres. The source text of this present paper is a folktale from Indonesian culture as well however it is from different province of Indonesia. The folktale in this paper is from Central Borneo. Consequently, the ideology presented and the phenomena observed might be different.

Other paper highlighting ideological reproduction was conducted by Jirata [22]. The paper observes how the children pass the norms and values that they acknowledge from their parents in a particular culture, Guji Omoro in Ethiopia. The fundamental notion is that the children are active agents of ideology reproduction. The researcher obtains the data by getting involved in social activities, especially in storytelling activities. The participants are twenty-six children in the society. The researcher listens to the children reproducing the ideologies and conforms them to the elder members of the society. The purpose of conforming is to check whether the children acknowledge and absorb the ideologies well. Interestingly, in the research the participants, who are children, are often engaged in a debate over the ideologies. The topical ideologies are that folktales as mirrors of the past, reflections of intergenerational change, and effects of heterogeneous values. In conclusion, the children do not only actively listen or hear the ideologies of the society but also reproduce and perform their conducts accordingly to the ideologies. The paper might present the possibility of folktales to be interpreted and reproduced. However, the paper does not use linguistic toolkits in the analysis. The present paper, the analysis employs linguistic toolkits. By using linguistic toolkits, the analysis would be more detailed and rigorous.

A paper by Ngoc Bui discusses the affirmation of particular ideologies in folktales [23]. The paper argues that those particular folktales are organized in order to confirm the existence and practice of particular conducts in particular society. The paper also argues that some folktales are influenced by the changes in society. The paper utilizes 
literature analysis in supporting the affirmation. The researcher observes specifically to the actions of particular characters in the folktales. The actions are then interrelated to the social rewards and punishment. In short, the paper confronts the reality and the intrinsic elements of the folktales. As the conclusion in the paper, the folktales are the depiction and reflection of ideologies and values of the society in literary works. Particularly, the ideologies are about the social contract and social evaluation about the society's unfortunates. Being different from the paper, this recent paper does not confront the social reality of the society. This paper only extracts the ideology in terms of moral value from the folktale. The extraction was done by analyzing the language choices in the folktale.

\section{METHOD}

This paper wants to examine the feasible reproduction of a folktale by first year students in English Letters Department. This section will discuss three items, namely the source text, the reproducer, and the methodology. The source text is in a form of folktale. The folktale is Bunanta's Ampak Dan Musang Yang Cerdik [3]. The folktale is selected due to two reasons. First, it is selected since it is from Central Borneo, Indonesia. Since Indonesia is rich of local stories, the object might exemplify folktales from Indonesia, which is translated into English. This reason suits with the participants who are studying English literatures. This story might expand their reading materials. Second, the story is selected since it belongs to children's literature, which it is not long and in which the language is simple.

The participants of this paper are second semester students in English Literature Department of Sanata Dharma University. In the second semester, the participants learn a subject entitled English Composition II. In this subject, the participants learn how to read and write various genres of texts. They do not only learn how to understand texts of particular genres but also learn to compose texts of those genres. They are familiarized with the generic structure of the texts. However, in English Composition II, the participants do not learn about narrative genres. Instead, they learn Recount genres which is quite similar in structure to narrative. However, in this research process, only four students returned their reproductions. Later on the reproductions are labelled by alphabets, namely Reproduction Text (later on it is referred as RT) A, RT B, RT C, and RT D.

To do the analysis, this paper follows specific procedures. First, the moral value/teaching was decided. Second, the source text was broken down into clauses since the objects of transitivity analysis are clauses and the processes in the clauses. Third, the processes were classified based on the types. After that, each type was interpreted based on its nature. Fourth, the language of evaluation in the folktale was identified. The language of evaluation observed the attitude toward the topical words. The language of evaluation was categorized based on whether it belongs to Affect, Judgment, or Appreciation. In the analysis the attitudes are symbolized into:

$$
\begin{aligned}
+ & =\text { positive attitude } \\
- & =\text { negative attitude } \\
\text { des } & =\text { affect: desire } \\
\text { hap } & =\text { affect: un/happiness } \\
\text { sec } & =\text { affect: in/security } \\
\text { sat } & =\text { affect: dis/satisfaction } \\
\text { norm } & =\text { judgement: normality } \\
\text { cap } & =\text { judgement: capacity } \\
\text { ten } & =\text { judgement: tenacity } \\
\text { ver } & =\text { judgement: veracity } \\
\text { prop } & =\text { judgement: propriety } \\
\text { reac } & =\text { appreciation: reaction } \\
\text { comp } & =\text { appreciation: composition } \\
\text { val } & =\text { appreciation: valuation }
\end{aligned}
$$

Fifth, the folktale was distributed to the participants. Each participant received a copy of the folktale. The distribution was first online, but none returned the reproduction. Therefore, the researcher distributed the folktale in person. Sixth, they read the folktale and rewrote the folktale by using their own languages. They were supposed to rewrite the folktale in no more than 30 sentences but no less than 20 sentences. This spatial limitation forced them to use the language with more consideration. Seventh, the third and fourth steps were applied to the reproduced texts.

\section{FINDING AND DISCUSSION}

The analysis and discussion will be presented in three subchapters. The first and the second present the transitivity analysis on both the source text and the RTs. The third subchapter elaborates the attitudinal use of language in both the source text and the RTs. In the discussion on the language in RTs, the similarities and differences in the findings are going to be elaborated.

\section{A. Transitivity Analysis on the Source Text}

The ideology in Bunanta's Ampak dan Musang yang Cerdik [3] is particular since it differs from common folktales. This is rather deviant from the conventional children's literature. The story does not tell the common moral values about the winning good characters. Though this folktale does not mention that the bad characters might win neither. Otherwise, the folktale tells the readers about the cunning character, the civet cat, which tried to achieve its goal. The civet cat conducted several tricks and deceived the other characters in the folktales. However, this paper does not analyze the ideology of being tricky and cunning. Instead, this paper focuses on the goal of the main characters, which is the wealth and prosperity.

The folktale, Bunanta's Ampak dan Musang yang Cerdik [3], might deliver an alternate value. This folktale narrates the main character's persistence in achieving the goal. The goal is being prosperous and wealthy. The ideology that is 
perused in this paper is derived from this goal. This paper is based on the definition of prosperous and wealthy presented in the folktale. The idea of being prosperous and wealthy is presented by the topics related to kingdom. It is told that the human character, Ampak, obeyed what the Musang said since he wanted to be prosperous by being a king.

This folktale clearly foregrounds the importance of being wealthy. By being rich and wealthy, somebody can possess more options in his/her life. On the contrary, the poor people are limited in their life options. Poor people needs protection and they need to do some acts to get protected. For instance, in the folktale, the ideas about wealth are foregrounded by the choice of words and the structure in which the words are located. The ideas of wealth are presented mostly by nouns referring to kingdom domain. Therefore, the analysis about the ideas of wealth should be the analysis on the participants. The ideas of poverty are presented mostly by verbs. After identifying the clauses containing the ideas of wealth and poverty, there are 38 clauses to analyze from the source text, including 30 clauses about wealth and 8 clauses about poverty.

TABLE 1. WORDS PRESENTING THE IDEAS OF WEALTH AND POVERTY

\begin{tabular}{|l|lr|}
\hline Wealth & \multicolumn{2}{|c|}{ Poverty } \\
\hline King; king Ampak; & was sound asleep, \\
King of Citrus Trees; & exhausted; $r$ & was \\
Kingdom; Prince; & frightened; frighten; \\
Princess; Princess's; & shivering; help; \\
the king; the King of & surprised and frightened; \\
Citrus; the palace; the & do to save; cannot \\
queen; two kingdoms; & defend; go and hide; \\
Your Highness & slipped; felt \\
\hline
\end{tabular}

After filtering the clauses in the source text by the presence of the topic words, the idea of wealth is configured by 53 processes. There are 23 material processes, 13 verbal processes, 13 relational processes, and four mental processes. The number signifies the prominent strategies in representing the ideology. The most prominent process is material process. This means the concept of wealth is mostly represented by actions of doing and happening. However, each process needs to be identified based on the configuration of the participants.

Table 2. Material Process Configuration Representing WEALTH

\begin{tabular}{|l|l|l|}
\hline No. & \multicolumn{1}{|c|}{ Process-Participants } & Occurances \\
\hline 1. & Process-Actor & 3 \\
\hline 2. & Process-Goal & 3 \\
\hline 3. & Process-Actor-Goal & 7 \\
\hline 4. & Process-Actor-Circumstance & 8 \\
\hline 5. & $\begin{array}{l}\text { Process-Actor-Goal- } \\
\text { Circumstances }\end{array}$ & 2 \\
\hline & Total & 23 \\
\hline
\end{tabular}

The most frequent occurrence of material process configuration is the configuration of Process-ActorCircumstance. This might be interpreted that wealth can be depicted by the absence of other participants of the process. The further interpretation can be derived from the location of the topical words depicting wealth. Only one out of the eight clauses places the topical words as the actor. Most of the time, the topical words about wealth is located in the circumstances. All the circumstances with topical words are place/spatial circumstances. This might mean that wealth becomes the destination.

The second most prominent process is the verbal process. In short, this process highlight saying process. Thus, wealth is highlighted by activities of saying. The most frequent Sayer is the cunning civet cat while the participant resembling the member of the kingdom becomes the targets and the receivers of the saying. This might be interpreted that the society members who want to achieve wealth are more outspoken in saying activities. Moreover, the verbiage(s) to the process always contain the topical words of wealth.

The third most prominent process is the relational process. By the number the frequency of relational process is equal to the verbal process. Further, the interpretation of the relational process would be more significant by observing whether the process gives attribution, possession, or identification. Mostly, the relationship between the participants is identification relation. There are seven clauses structured by this configuration, and the identifiers are always positive. The topical words are the identified. This might be interpreted that being wealth is positive. Four occurrences show Carriers-Attribute relationship. Interestingly, the Carriers are Ampak. In the story, Ampak, is the character who wanted to get the wealth by the help of the cunning civet cat. Thus, this might represent the condition that being prosperous and wealthy is ideal. One clause shows the PossessorPossessed relationship. The possessor is Ampak, who had been attributed as a King. He possessed all the goats. This might represent the condition of being prosperous and wealthy.

The least prominent process is mental process. Only four clauses show this process. Three out of them show the processes utilizing perception. The other one shows a desire. This representation creates such a distance between the sensers and phenomena. The sensers are 'only' able to perceive the phenomena. Further, the desire amplifies the distance. The senser has the desire to be the phenomenon. For instance, Ampak has a desire to see the King.

\section{B. Transitivity Analysis on the Reproduced Texts}

The reproduced texts are analyzed by utilizing the same toolkits and methodology as what the source text is analyzed. The reproduced texts are only seen by the transitivity processes that they employ in the texts. The number of sentences in each RT differ one another. Table 3 shows the number of sentences in each RT and sentences which include the topical words about prosperity and wealth. The number shows that the topic is pretty high in number. It means that the topic is prominent in the folktale.

Table 3. Number of Sentences in the ReProduced TeXts

\begin{tabular}{|l|l|l|l|}
\hline RT & $\begin{array}{c}\text { Number } \\
\text { of } \\
\text { Sentences }\end{array}$ & $\begin{array}{c}\text { Number of } \\
\text { Sentences with } \\
\text { Topical Words. }\end{array}$ & $\begin{array}{c}\text { Percentage } \\
(\%)\end{array}$ \\
\hline A & 29 & 17 & 58.62 \\
\hline B & 28 & 11 & 39.28 \\
\hline C & 20 & 10 & 50.00 \\
\hline D & 30 & 14 & 46.66 \\
\hline
\end{tabular}


The analysis takes account on the clauses containing the topical words. Each RT has different number of clauses containing the topical words. The number of clauses analyzed in this paper might be more than the number of clauses since each verb representing transitivity processes is accounted. The analysis also ignores the grammatical mistakes and errors produced by the participants. This paper does not also compare the RTs, instead, it considers them as a collection of data. Table 4 shows the number of clauses and processes in the RTs.

Table 4. Number of Clauses and Transitivity Processes in RTs

\begin{tabular}{|c|l|l|l|l|l|}
\hline RT & $\begin{array}{c}\text { Number } \\
\text { of } \\
\text { Clauses }\end{array}$ & $\begin{array}{c}\text { Material } \\
\text { Process }\end{array}$ & $\begin{array}{c}\text { Mental } \\
\text { Process }\end{array}$ & $\begin{array}{c}\text { Relation } \\
\text { al } \\
\text { Process }\end{array}$ & $\begin{array}{c}\text { Verbal } \\
\text { Proces } \\
\text { s }\end{array}$ \\
\hline A & 39 & 19 & 5 & 6 & 7 \\
\hline B & 22 & 5 & 5 & 8 & 4 \\
\hline C & 13 & 7 & 1 & 4 & 1 \\
\hline D & 24 & 9 & 2 & 5 & 8 \\
\hline Total & 96 & 40 & 13 & 23 & 20 \\
\hline
\end{tabular}

The most prominent process in the RTs is material process. This process appears almost by $50 \%$ of all. This frequency is in accordance to the frequency of material process in the source text. This might be interpreted that the topic about wealth is prominent in the source text in that the participants reproduce the concept in a similar manner. However, the detailed configuration of the material process need to be scrutinized further.

Table 5. Material Process Configuration Representing WEALTH IN RTS

\begin{tabular}{|l|l|l|}
\hline No. & Process-Participants & $\begin{array}{l}\text { Occur } \\
\text { ances }\end{array}$ \\
\hline 1. & Process-Actor & 5 \\
\hline 2. & Process-Goal & 1 \\
\hline 3. & $\begin{array}{l}\text { Proces-Goal- } \\
\text { Circumstances }\end{array}$ & 1 \\
\hline 4. & Process-Actor-Goal & 7 \\
\hline 5. & Process-Actor-Scope & 1 \\
\hline 6. & $\begin{array}{l}\text { Process-Actor-Scope- } \\
\text { Circumstances }\end{array}$ & 1 \\
\hline 7. & $\begin{array}{l}\text { Process-Actor- } \\
\text { Circumstance }\end{array}$ & 20 \\
\hline 8. & $\begin{array}{l}\text { Process-Goal- } \\
\text { Circumstances }\end{array}$ & 1 \\
\hline 9. & $\begin{array}{l}\text { Process-Actor-Goal- } \\
\text { Circumstances }\end{array}$ & 3 \\
\hline 10. & Total & 40 \\
\hline
\end{tabular}

The analysis shows that the participants successfully employ the same strategy in depicting the concept of wealth by employing material process. Table 5 is a recap of the material process configuration frequency in the RTs. The most significant configuration is Process-Actor-Circumstances configuration. This configuration is similar to the most frequent configuration in the source text. Therefore, again, the concept of wealth is mostly foregrounded by the Actors without the other participants.

The second most prominent process in the RTs is the relational process, and the third is verbal process. The frequency is higher than the verbal process. Meanwhile, in the source text, the relational process and verbal process share similar number of occurrence. Although they are not significantly different in number, this might be interpreted that relational process is more practical and strategic to represent the concept of wealth rather than verbal process in the RTs.

Similar to the finding in the source text, the least prominent process in representing the idea of wealth is the mental process. Since the RTs provide more clauses to analyze and the source text lacks of examples, the observation on this process might be significant in exemplifying the analysis of the source text. In the RTs, the mental process is represented by cognitive, perceptive, and desiderative processes. The most frequent mental process is perceptive mental process by six clauses. The second most prominent is cognitive mental process by four clauses, and the least process is the desiderative process by three clauses. This signifies the representation in the source texts. However, in the source text cognitive mental process does not appear. This shows the participants' own strategy in representing the concept of wealth.

\section{Attitudinal Analysis}

The attitudinal analysis is employed to observe the clauses containing the topical words related to prosperity and wealth. Thus, the data are similar to the transitivity analysis. However, the focus of this analysis is to observe the evaluation given to the idea. However, it turns out that attitudinal use of language is not really prominent to observe the idea of wealth. Only six items are found in the source text that present attitudes towards the idea of wealth.

Table 6. Attitudinal Analysis in the Source TeXt

\begin{tabular}{|c|c|c|c|c|c|}
\hline $\begin{array}{l}\text { Apprai } \\
\text { sing } \\
\text { items }\end{array}$ & $\begin{array}{l}\text { Apprai } \\
\text { ser }\end{array}$ & $\begin{array}{l}\text { Affe } \\
\text { ct }\end{array}$ & $\begin{array}{l}\text { Judg } \\
\text { e- } \\
\text { ment }\end{array}$ & $\begin{array}{l}\text { Appre- } \\
\text { ciation }\end{array}$ & $\begin{array}{l}\text { Apprai- } \\
\text { sed }\end{array}$ \\
\hline $\begin{array}{l}\text { Your } \\
\text { Highne } \\
\text { ss }\end{array}$ & Musang & - & - & + val & Princess \\
\hline Rich & $\begin{array}{l}\text { The } \\
\text { Princes } \\
\text { s }\end{array}$ & - & - & + val & Ampak \\
\hline $\begin{array}{l}\text { Amaze } \\
d\end{array}$ & - & - & - & $\begin{array}{l}\text { +reac- } \\
\text { Quality }\end{array}$ & $\begin{array}{l}\text { The } \\
\text { princess } \\
\text { and the } \\
\text { party }\end{array}$ \\
\hline $\begin{array}{l}\text { Luxurio } \\
\text { us }\end{array}$ & - & - & - & + val & $\begin{array}{l}\text { All the } \\
\text { furnishing }\end{array}$ \\
\hline $\begin{array}{l}\text { Happy } \\
\text { and gay }\end{array}$ & - & +hap & - & - & $\begin{array}{l}\text { The } \\
\text { people } \\
\text { from two } \\
\text { kingdoms }\end{array}$ \\
\hline $\begin{array}{l}\text { Wise } \\
\text { king }\end{array}$ & - & - & $\begin{array}{l}+ \text { pro } \\
\text { p }\end{array}$ & - & Ampak \\
\hline
\end{tabular}

From the data, the most prominent attitude is in a form of appreciation. Further, the attitudes are in positive values. This means that idea of wealth is highly appreciated in the source text. The other attitudes are positive happiness and positive propriety. However, the items do not closely resemble to the idea of prosperity and wealth since the occurrence is very limited. 
TABLE 7. NUMBER OF ATTITUdES IN THE RTS.

\begin{tabular}{|l|l|l|l|l|l|}
\hline & $\begin{array}{l}\text { +s } \\
\text { ec }\end{array}$ & $\begin{array}{c}\text { +pro } \\
\text { p }\end{array}$ & +val & $\begin{array}{l}\text { +Reac- } \\
\text { Quality }\end{array}$ & $\begin{array}{c}\text { +Reac- } \\
\text { Impact }\end{array}$ \\
\hline $\begin{array}{l}\text { Numb } \\
\text { er }\end{array}$ & 2 & 1 & 8 & 2 & 2 \\
\hline $\begin{array}{l}\text { Percen } \\
\text { tage } \\
(\%)\end{array}$ & 1.3 & 0.06 & $\begin{array}{l}53.3 \\
3\end{array}$ & 1.33 & 1.33 \\
\hline
\end{tabular}

The attitudinal analysis on the RTs presents similar results to the analysis on the source text. The most frequent attitude is valuation. The most frequent appraising item is the adjective rich. This appraising item, surely, highlights the idea of being prosperous and wealthy. However, interestingly, there are an attitude that appears in the RTs but not in the source text, namely security. In the RTs, the participants opt to attach the security to the character the Princes.

\section{CONCLUSION}

As a conclusion, the participants are successful in reproducing the idea of prosperity and wealth in the RTs. The participants employ similar strategies in representing the ideas. The transitivity analysis presents that the most frequent process in both the source text and the RTs is material process. This signifies that the verbs showing the process of doing and happening is strategic and effective in representing the idea of prosperity and wealth. However, in the RTs the relational process is higher in frequency rather than in the source text. Both in the source text and in the RTs, mental process is the least frequent process.

This paper is a part of a wider-in-scope research. This paper is a preliminary research to observe the tendency of folktale reproduction by English Literatures students. The data in this paper is very limited. Therefore, in the future, this paper will be more elaborated by observing more data and more participants. The linguistic toolkits in this paper are very limited as well, especially the language evaluation analysis. Hopefully, in the future research, the language evaluation might be more elaborative by including the other types of language evaluation.

A possible continuation of this paper would focus on the awareness of linguistic choices by students of English as Foreign Language (EFL). After having the tendency of the students in reproducing folktales and stories, researchers might conduct other observation towards students' linguistic choices and their vocabulary. Students with low-level of English proficiency might reproduce the stories by simpler words and expressions, while those with high-level proficiency are supposedly employ more complex vocabulary and expressions. Another possible future observation is observing the motivation of EFL students in choosing the linguistic items in reproducing stories. However, those researchers and observations are expected to be conducted in various contexts to acknowledge various EFL settings and conditions.

\section{References}

[1] Nodelman, Perry, The Hidden Adult. Baltimore: John Hopkins University Press, 2008.

[2] Fairclough, Norman, Critical Discourse Analysis: The Critical Study of Language. Essex: Longman Group Limited , 1995.

[3] Bunanta, Murti, Ampak dan Musang yang Cerdik. Jakarta: PT Gramedia Widiasarana Indonesia, 2011.

[4] Martin, J. R. and P.R.R White, The Language of Evaluation Appraisal in English. New York: Palgrave Macmillan, 2005.

[5] Matthiessen, Christian M.I.M. and M.A.K. Halliday, An Introduction to Functional Grammar. London: Hodder Arnold, 2004.

[6] Bradford, Richard. Stylistics. London: Routledge, 1997.

[7] Verdonk, Peter, Stylistics. Oxford: Oxford University Press, 2002.

[8] Black, Elizabeth, Pragmatic Stylistics. Edinburgh: Edinburgh University Press, 2006.

[9] Locke, Terry, Critical Discourse Analysis. London: International Publishing Group, 2004.

[10] Simpson, Paul, Language, Ideology, and Point of View. London: Routledge, 1993.

[11] Bennet, Andrew and Nicholas Royle, Introduction to Literature, Criticism, and Theory. Harlow: Longman, 2004.

[12] Bottigheimer, Ruth B, Fairy Tales A New History. Albany : University of New York Press, 2009.

[13] Haase, Donald, ed, The Greenwood Encyclopedia of Folktales and Fairy Tales. Vol. 1. London: Greenwood Press, 2008. 3 vols.

[14] Tatar, Maria, ed, The Classic Fairy Tales. London: W.W. Norton \& Company, Inc, 1999.

[15] Zipes, Jack, The Oxford Companion to Fairy Tales. Ed. Jack Zipes. Oxford: Oxford University Press, 2000.

[16] Zipes, Jack, Why Fairy Tales Stick The Evolution and Relevance of a Genre. London: Routledge, 2006.

[17] Mason, Victor. Balinese Children's Favorite Stories. Hongkong: Periplus Edition Limited, 2001.

[18] Phuoc, Tran Thi Minh, ed, Vietnamese Children's Favorite Stories . Singapore: Tuttle Publishing, 2015.

[19] Cunanan, T. Bonifacio, "Using transitivity as a framework in a stylistic analysis of Virginia Woolf's Old Mrs. Grey" in Asian EFL Journal, vol. 54, pp. 69-79, August 2011.

[20] Simpson, Paul, Stylistics A resource book for students. London: Routledge, 2004.

[21] Manggala, Simon Arsa. "The linguistic representation of ideology in a local folktale by English for International Communication Course students." in Conest 11. Proceeding. Jakarta: Atma Jaya University, 2014.

[22] Jirata, Tadesse Jaleta, "Children as interpreters of culture: producing meanings from folktales in southtern Ethiopia." In Journal of Folklore Research, vol. 48.3, pp. 269-292, September/December 2011.

[23] Ngoc Bui, Tran Quynh. "The social contract and symbolic structure in three Vietnamese tales of the 'Last Born'." in Asian Ethnology vol. 69.2, pp. 293-310, 2010. 